\title{
Construction and characterization of a truncated tissue factor-coagulation-based composite system for selective thrombosis in tumor blood vessels
}

\author{
PEILAN XU, MINGYUAN ZOU, SHENGYU WANG, TINGTING LI, CONG LIU, \\ LI WANG, LANLAN WANG, FANGHONG LUO, TING WU and JIANGHUA YAN \\ Cancer Research Center, School of Medicine, Xiamen University, Xiamen, Fujian 361102, P.R. China
}

Received March 27, 2019; Accepted July 24, 2019

DOI: $10.3892 /$ ijo.2019.4855

\begin{abstract}
The selective induction of tumor vascular thrombosis using truncated tissue factor (tTF) delivered via a target ligand is a promising novel antitumor strategy. In the present study, an anti-neuropilin-1 (NRP-1) monoclonal antibody (mAb)-streptavidin (SA):tTF-biotin (B) composite system was established. In this system, anti-NRP-1-mAb located tTF to the tumor vascular endothelial cell surface and induced vascular embolization. Due to their high binding affinity, SA and B were used to enhance thrombogenic activity. mAb was conjugated with SA using a coupling method with water-soluble 1-ethyl-3-(3-dimethylaminopropyl) carbodiimide and $\mathrm{N}$-hydroxysulfosuccinimide. Biotinylated tTF (tTF-B) was prepared using a B-labeling kit subsequent to the generation and purification of fusion protein tTF. Confocal microscopy and flow cytometry indicated that the anti-NRP-1-mAb-SA conjugate retained $\mathrm{mAb}$ targeting activity. The preservation of B-conjugate binding capacity was confirmed using a competitive ELISA, and factor X-activation analysis revealed that tTF-B retained the procoagulant activity exhibited by tTF. Live imaging was performed to assess mAb-SA distribution and tumor-targeting capability, and this yielded promising results. The results of in vivo studies in mice with subcutaneous xenografts demonstrated that this composite system significantly induced tumor vascular thrombosis and inhibited tumor growth, whereas these histological changes were not observed in normal organs.
\end{abstract}

Correspondence to: Dr Jianghua Yan or Dr Ting Wu, Cancer Research Center, School of Medicine, Xiamen University, 422 Xiangan South Road, Xiamen, Fujian 361102, P.R. China E-mail: jhyan@xmu.edu.cn

E-mail: wuting78@aliyun.com

Key words: vascular targeting therapy, anti-neuropilin-1 monoclonal antibody, truncated tissue factor, streptavidin-biotin system, thrombosis

\section{Introduction}

Tumor progression and metastasis relies on the delivery of sufficient oxygen and nutrients via blood vessels (1). Selectively inducing thrombosis in tumor vasculature, leading to tumor infarction, is an effective and promising antitumor strategy (2). Over the past 20 years, encouraging research into a new vascular targeting therapy has emerged $(3,4)$. In this strategy, truncated tissue factor (tTF) is used as a mediator and an extracellular domain of tissue factor (TF). TF is a major initiator of thrombogenic cascades (5). As a recombinant form of TF, tTF only contains the cell surface domain and exhibits less $\left(1 \times 10^{5}\right)$ factor $\mathrm{X}$ activity compared with TF in the phospholipid membrane (6). Both the intrinsic and extrinsic blood coagulation pathways lead to activation of coagulation factor X (7); activated factor $\mathrm{X}$ then converts prothrombin to thrombin, which finally accumulates in the generation of fibrin polymers and blood clots. tTF exhibits limited ability to activate factor $\mathrm{X}$; however, $\mathrm{tTF}$ can recover its native function and initiate local thrombosis once bound to the cell surface (negatively charged phospholipid) using a targeting agent (8). This targeting agent may be an antibody or a peptide ligand. Numerous biochemical conjugates and recombinant fusion proteins associated with tTF have been synthesized, and have been demonstrated to exhibit potential antitumor activity $(9,10)$. However, the use of tTF-ligand has certain limitations. Due to the low affinity of the targeting moiety in tumors, the undesirable tumor-specific targets often fail to induce complete thrombosis (11). Identification of additional targeting ligands or tumor-specific receptors may be required to enhance therapeutic efficacy.

Neuropilin-1 (NRP-1) is a non-tyrosine kinase transmembrane receptor of 120-130 kDa. This glycoprotein, first characterized as the receptor of neuronal semaphorin $3 \mathrm{~A}$, was subsequently revealed to be a co-receptor of vascular endothelial growth factor (VEGF)165 (12). Therefore, NRP-1 may indirectly enhance the biological activities of VEGF, including promoting the migration and angiogenesis of human umbilical vein endothelial cells (HUVECs) (13). Furthermore, NRP-1 expression has been revealed to be upregulated in a variety of tumor types, including hepatocellular carcinoma and breast cancer, and has been associated with poor 
prognosis (14-16). Due to the association of NRP-1 with tumor promotion, NRP-1 appears to be a promising angiogenesis target. However, conjugated antibody-tTF often cannot induce complete thrombosis due to this antibody only solving the issue of specific delivery $(17,18)$. The distribution of vascular targets (antigens or receptors) in the tumor vasculature is a major factor affecting tTF concentration (19). In the present study, the accumulation of tTF in tumor blood vessels was increased using the streptavidin (SA)-biotin (B) system, which was introduced to promote coagulation efficiency.

$\mathrm{SA}$ is a $60-\mathrm{kDa}$ tetrameric protein generated from Streptomyces avidinii, and is commercially available at a high purity and exhibits favorable in vivo stability $(20,21)$ The binding affinity of SA for B, a 244-kDa vitamin, is high $\left(\mathrm{Kd}=10^{-15} \mathrm{~mol} / \mathrm{l}\right)(22)$. Due to the rapid association and strong interaction between $\mathrm{SA}$ and $\mathrm{B}$, these molecules have been widely used as binding pairs in analysis, drug delivery systems and pre-targeting radioimmunotherapy (23-28).

In the present study, a novel tumor vasculature-targeting approach was explored. This strategy consisted of an SA-conjugated anti-NRP-1 monoclonal antibody (mAb-SA) and biotinylated tTF (tTF-B). Anti-NRP-1 mAb (mAb), which was previously generated via the hybridoma technique in the laboratory (29), was conjugated to SA to pre-target the NRP-1 receptors on the tumor vascular endothelial cell surface. mAb-SA diffused into the tumor area, and tTF-B was subsequently administered and efficiently combined with $\mathrm{mAb}-\mathrm{SA}$ to induce local tumor thrombosis. To explore the therapeutic feasibility of this two-step coagulation approach, in vitro studies were performed to assess the targeting ability of $\mathrm{mAb}-\mathrm{SA}$ and procoagulant activity of $\mathrm{tTF}-\mathrm{B}$, and to compare the B/SA binding capacity between $\mathrm{mAb}-\mathrm{SA}$ and $\mathrm{tTF}-\mathrm{B}$. Live imaging was used to investigate the distribution and in vivo tumor-binding ability of mAb-SA. Antitumor activity and coagulation efficiency was subsequently evaluated via in vivo assessments and histological analysis.

\section{Materials and methods}

Materials. Anti-NRP-1 mAb with a high purity was produced using the hybridoma technique and preserved in the laboratory after freeze-drying (29). 2-(N-morpholino) ethane sulfonic acid (MES), 1-ethyl-3-(3-dimethylaminopropyl) carbodiimide (EDC), N-hydroxysulfosuccinimide (sulfo-NHS), streptavidin (SA), Sephadex G200 and a Sephadex G200 column $(1.5 \times 22 \mathrm{~cm})$ were purchased from Sigma-Aldrich (Merck KGaA). GoldBand 3-color Regular Range Protein Marker (10-180 kDa) was purchased from Shanghai Yeasen Biotechnology Co., Ltd. Endothelial cell medium (ECM) containing human epidermal growth factor was purchased from Shanghai Zhong Qiao Xin Zhou Biotechnology Co., Ltd. DMEM and FBS were purchased from Invitrogen (Thermo Fisher Scientific, Inc.). Mouse IgG isotype (cat. no. 0107-01) was obtained from AmyJet Scientific Inc. Rhodamine B isothiocyanate (RBITC)-conjugated goat anti-mouse IgG (cat. no. D111097), isopropyl-l-thio-B-d-galactopyranoside (IPTG), BSA, Hoechst 33258 powder, and hematoxylin and eosin (H\&E) were purchased from Sangon Biotech Co., Ltd. Factors X and VII were obtained from Sigma-Aldrich (Merck KGaA). pET22b (+) plasmid and E. coli BL21(DE3) were purchased from Novagen (Merck KGaA). cDNA encoding for $\mathrm{tTF}$, containing amino acids 1 to 218 of human TF, was used to generate the tTF expression vector tTF-pET22b (+) via PCR using the following primers: Forward, 5'-TCCATGGGC TCTGGCACTACA-3' and reverse, 5'-GTGCTCGAGTTC TCTGAATTCC-3'. NcoI and XhoI restriction enzymes were used to insert cDNA into the plasmid. Nickel-nitrilotriacetic acid (Ni-NTA) agarose was purchased from Qiagen, Inc. A B-labeling kit was obtained from Wuhan Elabscience Biotechnology Co., Ltd. Cyanine-5 (Cy5) NHS-ester was purchased from Tiangen Biotech Co., Ltd.

Preparation of $m A b-S A$ conjugate. The purity of anti-NRP-1 $\mathrm{mAb}$ was first identified via $12 \%$ SDS-PAGE. As presented in Fig. 1, the mAb-SA conjugate was synthesized using a coupling method (30). The concentration of $\mathrm{mAb}$ was adjusted to $3 \mathrm{mg} / \mathrm{ml}$ with reaction buffer $(0.1 \mathrm{~mol} / 1 \mathrm{MES} ; 0.5 \mathrm{~mol} / 1$ $\mathrm{NaCl}$; pH 6.0) according to the improved Bradford method. A total of $3.83 \mathrm{mg}(0.02 \mathrm{mmol})$ of EDC and $4.34 \mathrm{mg}(0.02 \mathrm{mmol})$ of sulfo-NHS were weighed and immediately transferred to the reaction solution $(1 \mathrm{ml})$. The solution was mixed and stirred at room temperature for $15 \mathrm{~min}$. SA concentration was adjusted to $1.2 \mathrm{mg} / \mathrm{ml}$ with $0.1 \mathrm{~mol} / \mathrm{l}$ potassium phosphate buffer ( $\mathrm{pH} 7.5$ ), and $1 \mathrm{ml} \mathrm{SA}$ was added to the reaction buffer. Nitrogen gas was purged into the solution for $3 \mathrm{~min}$ and the beaker was then sealed. The reaction was subsequently left to proceed at room temperature for $2 \mathrm{~h}$, then purified using a Sephadex G200 column as previously described $(31,32)$, with some modifications. Briefly, Sephadex G200 was swelled in a boiling water bath for $2 \mathrm{~h}$ and cooled. Pretreated Sephadex G200 was poured into the column slowly, with no air mixing in, and equilibrated with pure water $(\mathrm{pH} \mathrm{7.5)}$ for $40 \mathrm{~min}$. The crude product was then slowly added to the column and eluted with pure water at a rate of $0.2 \mathrm{ml} / \mathrm{min}$. Eluted samples $\left(1.5 \mathrm{ml} /\right.$ tube) were collected and read with a NanoDrop ${ }^{\mathrm{TM}}$ 2000 spectrophotometer (NanoDrop Technologies; Thermo Fisher Scientific, Inc.) at $280 \mathrm{~nm}$. All purification steps were conducted at $4^{\circ} \mathrm{C}$. Native $8 \%$ PAGE was performed to confirm whether conjugated protein had been successfully isolated (33).

Cell culture. HUVECs and the human liver cancer cell line HepG2, which both overexpress NRP-1 $(34,35)$, were obtained from the American Type Culture Collection. HUVECs were used for in vitro experiments, and HepG2 cells were used to establish a mouse tumor model. HepG2 cells were cultured in high-glucose DMEM supplemented with $1 \%$ penicillinstreptomycin and 10\% FBS. HUVECs were cultured in ECM containing human epidermal growth factor. All cells were incubated in a humidified atmosphere with $5 \% \mathrm{CO}_{2}$ at $37^{\circ} \mathrm{C}$.

Confocal immunofluorescence. HUVECs $\left(1 \times 10^{5}\right.$ cells $\left./ \mathrm{ml}\right)$ were seeded into a 6 -well culture plate with one glass coverslip per well. The cells were then incubated and subsequently washed with PBS (pH 7.4) three times, until 50\% cloning efficiency had been reached. The cells were then fixed with $1 \mathrm{ml}$ $4 \%$ paraformaldehyde at $4^{\circ} \mathrm{C}$ for $30 \mathrm{~min}$ and washed with PBS three times. A total of $2 \mathrm{ml}$ PBS containing $\mathrm{mAb}, \mathrm{mAb}-\mathrm{SA}$ or a mouse $\operatorname{IgG}$ isotype control $(1: 5,000)$ was added, and the cells were cultured at $37^{\circ} \mathrm{C}$ for $1 \mathrm{~h}$. After washing, cells were cultured with a goat anti-mouse RBITC mAb $(1: 200)$ at $37^{\circ} \mathrm{C}$ 


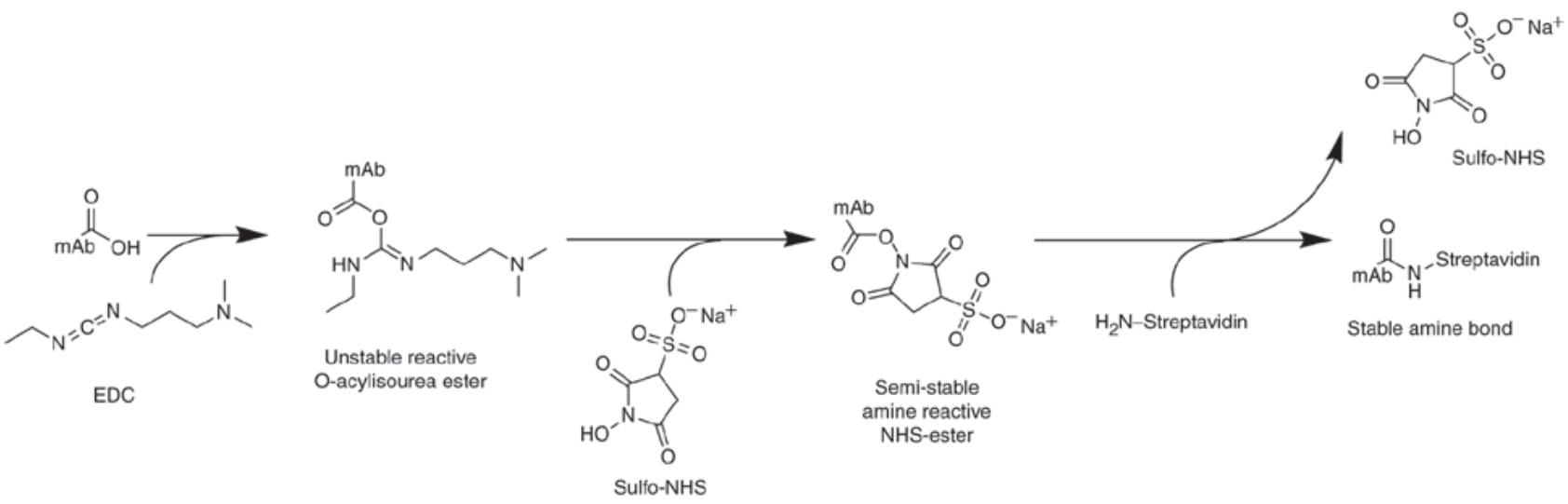

Figure 1. Formation of the mAb-SA conjugate via the EDC reaction. SA was conjugated to mAb using a two-step cross-linking procedure with zero-length heterobifunctional cross-linkers. mAb, monoclonal antibody; SA, streptavidin; EDC, 1-ethyl-3-(3-dimethylaminopropyl) carbodiimide; sulfo-NHS, N-hydroxysulfosuccinimide.

for an additional $1 \mathrm{~h}$ in the dark. Hoechst 33258 was used to stain cell nuclei at $37^{\circ} \mathrm{C}$ for $5 \mathrm{~min}$ and the samples were then examined under a FV1000MPE-B confocal microscope (Olympus Corporation) and photographed. Five random fields per sample were analyzed (magnification, x600).

Flow cytometry. Semiquantitative analysis was conducted to further assess the ability of the mAb-SA conjugate to target NRP-1. HUVECs were removed from the culture plate using trypsin and washed with PBS three times. The cells were then fixed with $1 \mathrm{ml} 4 \%$ paraformaldehyde at $4^{\circ} \mathrm{C}$ for $30 \mathrm{~min}$ and washed with PBS three times. After being resuspended in PBS, cells were incubated with $\mathrm{mAb}, \mathrm{mAb}-\mathrm{SA}$ or the mouse IgG isotype $(1: 5,000)$ control at $37^{\circ} \mathrm{C}$ for $1 \mathrm{~h}$ and incubated with the anti-mouse RBITC mAb (1:200) at $37^{\circ} \mathrm{C}$ for a further $1 \mathrm{~h}$. Each sample of 10,000 cells was analyzed using a CytoFlex S flow cytometer (Beckman Coulter, Inc.). Results were analyzed using CytExpert version 2.0 (Beckman Coulter, Inc.).

Production of fusion protein tTF. E. coli (BL21; DE3) containing tTF expression vector were cultured in Luria broth supplemented with $1 \%$ ampicillin. IPTG was added when the germiculture reached $0.6-0.8$ at $600 \mathrm{~nm}$ to induce the expression of the fusion protein tTF. After stimulation for $6 \mathrm{~h}$, bacterial cells were collected and centrifuged at $12,000 \mathrm{x} \mathrm{g}$ at $4^{\circ} \mathrm{C}$ for $20 \mathrm{~min}$. A total of $5 \mathrm{ml}$ lysis buffer $(20 \mathrm{mmol} / \mathrm{l}$ Tris/HCl; pH 8.0; 0.5 mol/1 NaCl; 2 mol/l urea; 20 ml/1 Triton $\mathrm{X}-100)$ per gram (wet weight) was subsequently added. After incubating for $90 \mathrm{~min}$, cells were centrifuged at $12,000 \mathrm{x} \mathrm{g}$ for $20 \mathrm{~min}$ at $4^{\circ} \mathrm{C}$. The pellet was resuspended and sonicated (sonication time: $5 \mathrm{sec}$; interval time: $5 \mathrm{sec}$ ) in washing buffer (20 mmol/1 Tris/HCl; pH 8.0; $0.5 \mathrm{~mol} / 1 \mathrm{NaCl} ; 2$ mol/1 urea; $20 \mathrm{ml} / 1$ Triton X-100) at $4^{\circ} \mathrm{C}$ for $30 \mathrm{~min}$. A total of $5 \mathrm{ml}$ solubilization buffer $(20 \mathrm{mmol} / 1 \mathrm{Tris} / \mathrm{HCl}$; pH 8.0; 8 mol/l urea; $1 \mathrm{mmol} / 1 \beta$-mercaptoethanol; $20 \mathrm{ml} / 1$ Triton $\mathrm{X}$-100) per gram (wet weight) was added to dissolve the inclusion bodies. After incubation at room temperature overnight, the suspension was centrifuged at $12,000 \mathrm{xg}$ for $20 \mathrm{~min}$ at $4^{\circ} \mathrm{C}$. The supernatant was then purified with a Ni-NTA column according to the protocol of the His-Bind Buffer kit (Novagen; Merck KGaA). The products were analyzed using 12\% SDS-PAGE under denaturing conditions. The purified fusion protein tTF was then concentrated using a Centrifugal Filter and freeze-dried for subsequent use.

Factor Xactivation. tTF-B was prepared using a B-labeling kit according to the manufacturer's protocol. A factor $\mathrm{X}$ activation assay was performed to assess the coagulation activity of tTF-B, as previously described (36). Various concentrations (0.01-10 $\mu \mathrm{mol} / \mathrm{l})$ of BSA, tTF or tTF-B were incubated with $100 \mathrm{nmol} / 1$ factor VII in Tris-buffered saline at $37^{\circ} \mathrm{C}$ for $10 \mathrm{~min}$. Factor X $(5 \mathrm{nmol} / \mathrm{l})$ was then added, and the mixture was incubated for $10 \mathrm{~min}$ at room temperature. The reaction was subsequently quenched using $100 \mathrm{mmol} / \mathrm{l}$ EDTA. A total of $2 \mathrm{nmol} / \mathrm{l}$ Spectrozyme FXa was added to the mixture, and the absorbance was detected at $405 \mathrm{~nm}$ after $3 \mathrm{~min}$.

ELISA. A competitive ELISA was performed to determine the B/SA-binding capacity of mAb-SA/tTF-B. A 96-well plate was coated with tTF-B $(100 \mu \mathrm{l} /$ well; $20 \mu \mathrm{g} / \mathrm{ml})$ in coating buffer $(7.5 \mathrm{mM}$ sodium carbonate; $17.4 \mathrm{mM}$ sodium bicarbonate; $\mathrm{pH} 9.6$ ) and incubated overnight at $4^{\circ} \mathrm{C}$. The plate was then washed three times with PBS-Tween solution (0.01 mol/1, pH 7.4, 0.05\% Tween-20), and 10\% FBS was then used to block the unbound sites at $37^{\circ} \mathrm{C}$ for $1 \mathrm{~h}$. After washing the plate five times, HRP-labeled SA $(100 \mu \mathrm{l} / \mathrm{well} ; 200 \mu \mathrm{g} / \mathrm{ml})$ and was added to each well to serve as the competitor. Serially diluted mAb-SA or SA $(100 \mu \mathrm{l} / \mathrm{well} ; 200-12.5 \mu \mathrm{g} / \mathrm{ml})$ was then added separately. After incubation for $1 \mathrm{~h}$ at $37^{\circ} \mathrm{C}$, the enzyme substrate orthophenylenediamine, in $50 \mathrm{mM}$ phosphate-citrate buffer ( $\mathrm{pH} 5.0$ with fresh $30 \%$ hydrogen peroxide) and at a concentration of $0.4 \mathrm{mg} / \mathrm{ml}$, was added (100 $\mu \mathrm{l} /$ well). The plate was subsequently incubated at room temperature for $20 \mathrm{~min}$, and $1 \mathrm{M} \mathrm{H}_{2} \mathrm{SO}_{4}$ was added to quench the reaction $(50 \mu \mathrm{l} /$ well). Absorbance values were measured at $490 \mathrm{~nm}$. The inhibition rate was calculated according to a previous study (37) to determine the immunoreactivity of mAb-SA.

Mouse tumor models. Female BALB/c nude mice $(n=60$, 6-8 weeks old, 18-22 g) were purchased from the Experimental Animal Center of Xiamen University, of which 52 were 
ultimately used for experiments. HepG2 cells were dissociated in a culture plate using $10 \%$ trypsin at $37^{\circ} \mathrm{C}$ for $3 \mathrm{~min}$, and subsequently resuspended in PBS. Each mouse was then subcutaneously injected in the right flank with $100 \mu$ l HepG2 cells $\left(1 \times 10^{6}\right)$. Animals were housed in the Experimental Animal Center under specific pathogen-free conditions: Temperature, 22-25 ${ }^{\circ}$; humidity, 50-60\%; 12-h light/dark cycle. Mice had free access to water and Purina 5L79 rodent chow. Animal health and behavior were monitored daily. Animal welfare was in accordance with institutional guidelines. When the mean tumor volume [calculated as (length $\mathrm{x}$ width $\left.{ }^{2}\right) / 2$ )] reached $150-250 \mathrm{~mm}^{3}$, those mice were used for live imaging, antitumor activity studies and histological analysis after being acclimatized. The largest subcutaneous tumor observed in the present study was $1.9 \mathrm{~cm}$ in diameter at its widest point, and no mice exhibited multiple subcutaneous tumors. According to a previous study (38), the humane endpoints were determined based on the mouse weight loss ( $>20 \%$ of total body weight) or mouse activity assessment (hunching, stationary, ruffling and poor grooming), and mice were euthanized via cervical dislocation and dissected. The duration of the animal experiment was $\sim 25$ days. Then, all remaining mice were euthanized by cervical dislocation, and no mice were found dead. All animal experiments performed in the present study were approved by the Ethics Committee of Xiamen University.

Fluorescent labeling. SA, anti-NRP-1 mAb and mAb-SA were labeled with fluorescein. The concentration of Cy5 NHS-ester used was $1 \mathrm{mg} / \mathrm{ml}$ in DMSO. According to the total amount of proteins (SA, anti-NRP-1 mAb or mAb-SA), $0.01 \mathrm{mg}$ fluorescein per mg protein were mixed at room temperature for $2 \mathrm{~h}$. Dialysis was performed to remove unlabeled Cy5 NHS-ester for $4 \mathrm{~h}$ at room temperature and subsequently at $4^{\circ} \mathrm{C}$ overnight with $0.15 \mathrm{~mol} / 1 \mathrm{NaCl}$ solution. The whole process was performed in the dark.

In vivo imaging. To investigate the in vivo distribution of mAb-SA, nude mice with subcutaneous xenografts were randomly divided into four groups ( $n=3 /$ group). Mice in each group were intravenously injected with $100 \mu$ l saline, SA-Cy5, anti-NRP-1 mAb-Cy5, or mAb-SA-Cy5 via the tail vein. After the mice were anesthetized in $1.5 \%$ isoflurane, the Cy5 fluorochrome was then detected in mice using an Imaging IVIS-200 system (PerkinElmer, Inc.) at 0.5, 3, 6, 12, 24, 36, 48 and $72 \mathrm{~h}$. The nude mice were sacrificed after imaging. Tumor tissues and major organs, including the heart, liver, spleen, lungs, kidneys and brain, were isolated from the mAb-SA-Cy5 treatment group, and their fluorescent signal intensity was measured using Living Image version 4.3 (Caliper Life Sciences, Inc.; PerkinElmer, Inc.).

Antitumor efficacy evaluation. Nude mice bearing $150 \pm 50 \mathrm{~mm}^{3}$ HepG2 tumors were randomly assigned to four groups ( $n=10 /$ group). Mice in each group received four intravenous administrations of saline, mAb-SA, tTF-B and $\mathrm{mAb}-\mathrm{SA}: \mathrm{tTF}-\mathrm{B}$, at 3-day intervals, at a dose of $5 \mathrm{mg} / \mathrm{kg}$. In the mAb-SA:tTF-B treatment group, tTF-B was injected $24 \mathrm{~h}$ after each administration of $\mathrm{mAb}-\mathrm{SA}$. Tumor size was measured every second day. Tumor tissues were surgically removed and weighed after 12 days of treatment.
Histological analysis. To evaluate the tumor vascular targeting ability of the mAb-SA:tTF-B composite system and its effects on intravascular thrombosis in vivo, tumors from different treatment groups and major organs from the mAb-SA:tTF-B group were fixed in $4 \%$ formaldehyde solution at room temperature for $48 \mathrm{~h}$ before embedding in paraffin and cutting into $5-7-\mu \mathrm{m}$ sections for Harris $\mathrm{H} \& \mathrm{E}$ staining. Tissues were stained with hematoxylin and eosin at room temperature for $3 \mathrm{~min}$ and $20 \mathrm{~min}$, respectively. Five random fields per sample were examined under a light microscope (magnification, x200).

Statistical analysis. All data in the present study were analyzed using Prism 6.0 (GraphPad Software, Inc.) and presented as the mean \pm standard deviation. One-way ANOVA with Tukey's multiple comparison post hoc test was performed to assess the differences among groups. $\mathrm{P}<0.05$ was considered to indicate statistically significant differences.

\section{Results}

Preparation of $m A b-S A$ conjugate via $E D C$ reaction and purification using gel-filtration. As presented in Fig. 2A, the purity of anti-NRP-1 mAb reached $\sim 95 \%$. To separate the desired synthetic product from any impurities, including the cross-linked byproduct, any unreacted antibodies and the unreacted SA, the crude products were purified using a Sephadex G200 gel-filtration column, which was washed using pure water ( $\mathrm{pH}$ 7.5). To avoid dissociation to monomeric species, the conjugate was analyzed using native $8 \%$ PAGE under a non-boiled condition. The bands shown in Fig. 2B correspond to (from left to right) unreacted SA, unreacted $\mathrm{mAb}$ and conjugate products after purification. The final purified conjugate was well-defined and clear.

Confocal immunofluorescence and flow cytometry demonstrate the in vitro NRP-1 targeting ability of $m A b-S A$. Confocal immunofluorescence and flow cytometry were performed to determine whether mAb-SA maintained biological targeting activity. As presented in Fig. 3A, red fluorescence of RBITC was observed on the surface membrane of HUVECs treated with $\mathrm{mAb}$ or $\mathrm{mAb}-\mathrm{SA}$. This result indicated that mAb-SA was able to bind with NRP-1 on the cell surface. The results of flow cytometry (Fig. 3B) were similar to those of the confocal experiment. The anti-NRP-1 mAb and mAb-SA groups exhibited significant HUVEC-binding activity. The NRP-1-binding capacity of mAb-SA was almost equivalent to that of mAb.

Preparation and purification of tTF fusion protein. To optimize the culture conditions, various concentrations (0-1 mmol/1) of IPTG were used. $12 \%$ SDS-PAGE was performed to evaluate the induced fusion protein yield (Fig. 4). A maximum yield was observed when the IPTG concentration reached $0.8 \mathrm{mmol} / 1$. The fusion protein was expressed in the form of inclusion bodies. The inclusion bodies were washed with washing buffer and subsequently dissolved in denaturation buffer. A nickel affinity column was used to purify the soluble products. As presented in Fig. 4, the objective fusion protein was $\sim 34 \mathrm{kDa}$ with $\sim 99 \%$ purity. 
A

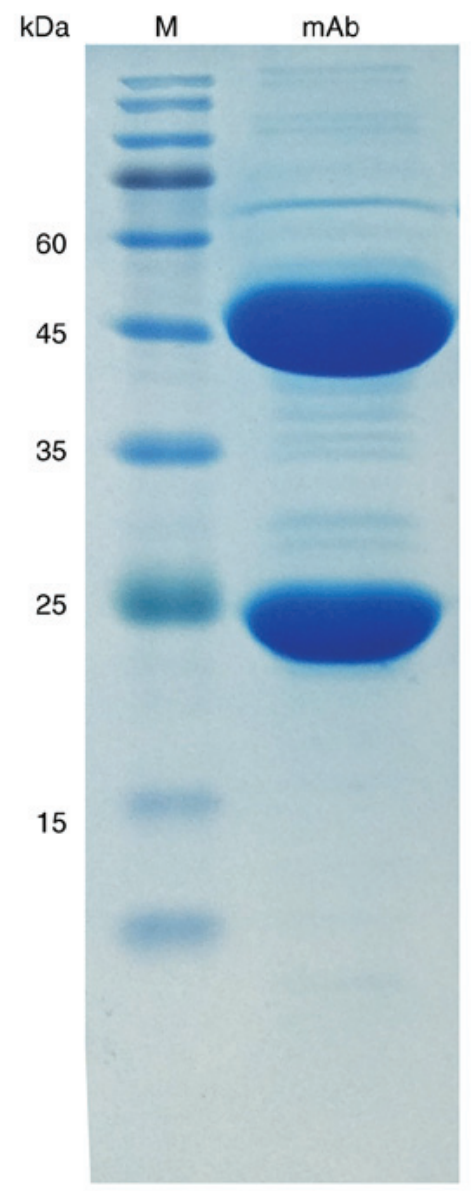

B

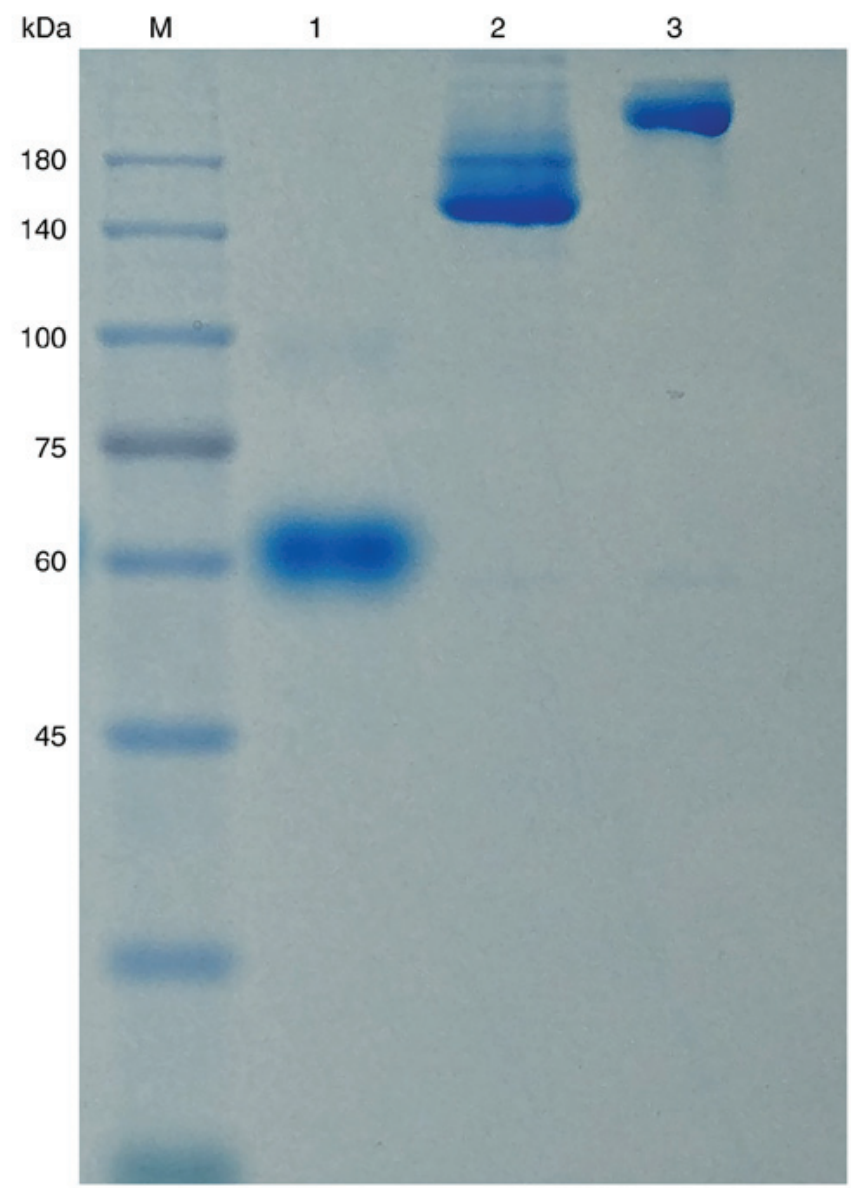

Figure 2. Preparation and purification of mAb-SA. (A) SDS-PAGE analysis showed that the purity of anti-NRP-1 mAb reached $\sim 95 \%$. Heavy and light chain bands were observed at $\sim 45$ and $\sim 25 \mathrm{kDa}$, respectively. (B) Synthetic products were characterized using native $8 \%$ PAGE. Lane 1, SA (60 kDa) before conjugation; lane 2, anti-NRP-1 mAb ( 150 kDa) before conjugation; lane 3, final purified conjugate mAb-SA ( 210 kDa). mAb, monoclonal antibody; SA, streptavidin; NRP-1, neuropilin-1; M, protein marker.
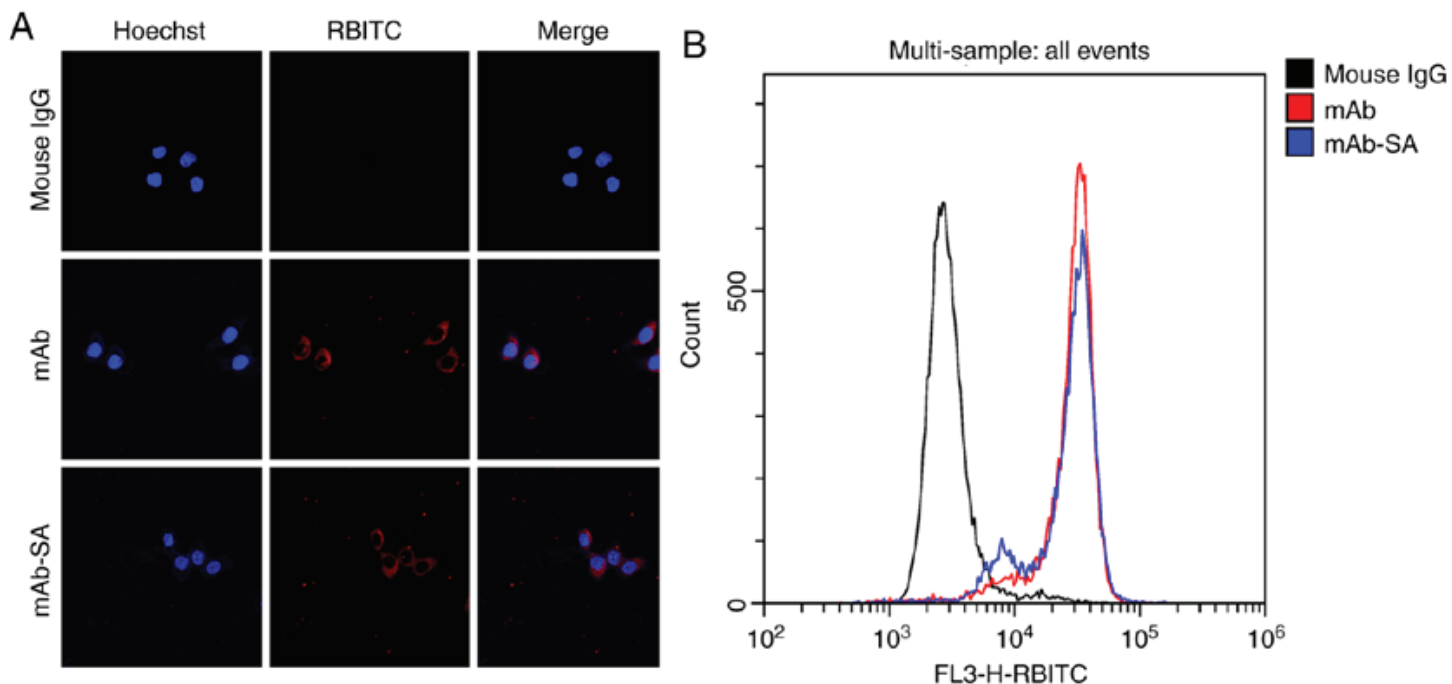

Figure 3. Functional characterization of mAb-SA. (A) Targeting ability of mAb-SA was analyzed using confocal immunofluorescence. mAb and mAb-SA bound to the surface of HUVECs, whereas the negative control (mouse IgG) did not. (B) Flow cytometry was performed to further evaluate the targeting capacity of mAb-SA. Cell count curves with different fluorescence intensities were shown. mAb (red curve); mAb-SA (blue curve); negative control (black curve). RBITC, Rhodamine B isothiocyanate; mAb, monoclonal antibody; SA, streptavidin; HUVECs, human umbilical vein endothelial cells.

$t T F-B$ promotes blood coagulation in vitro. A factor $\mathrm{X}$ activation assay was performed to evaluate the retention of blood coagulation activity in tTF-B. As presented in Fig. 5, tTF and tTF-B exhibited similar factor $\mathrm{X}$ activity at the corresponding 


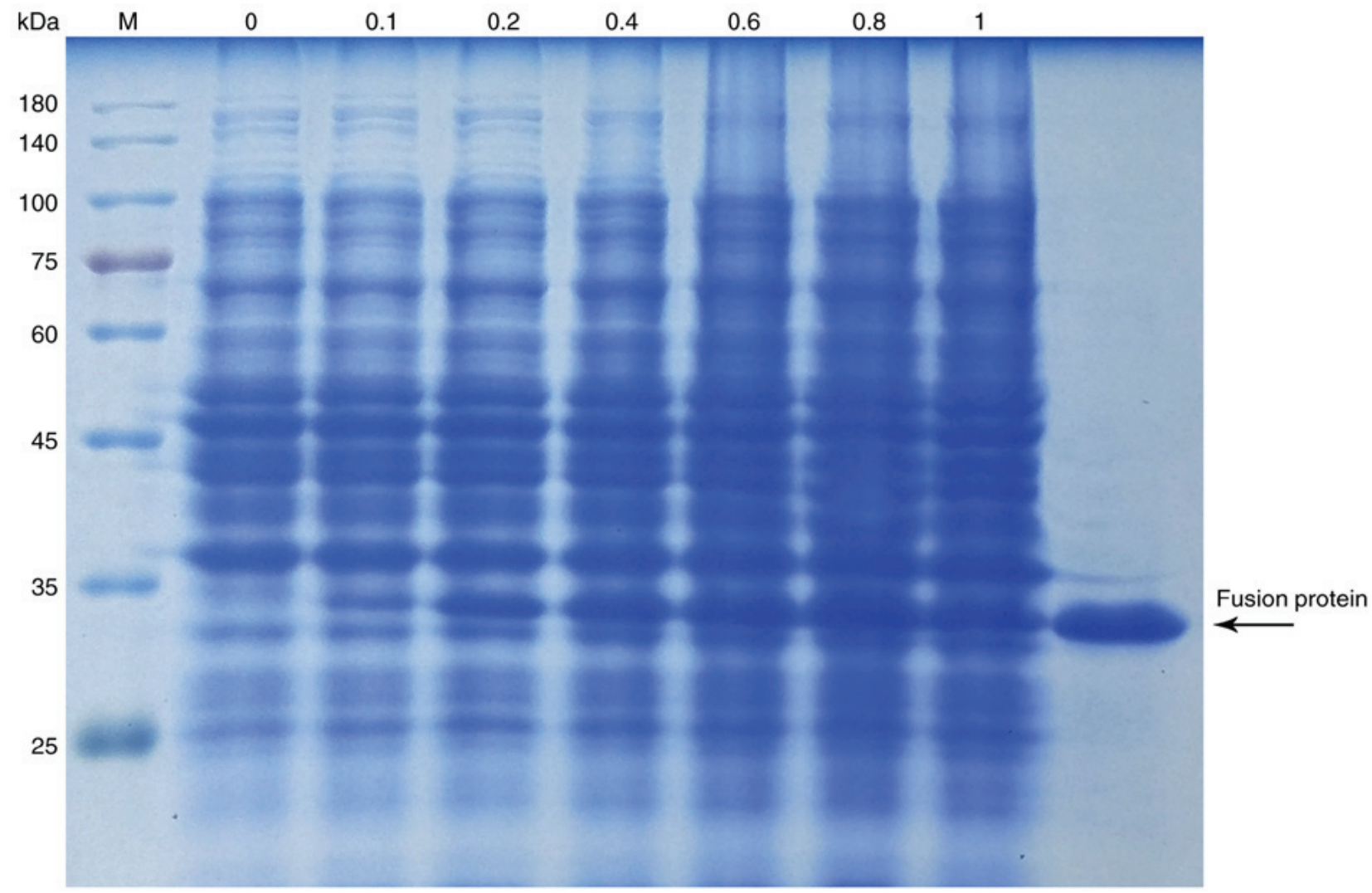

Figure 4. SDS-PAGE analysis of the expression and purification of the fusion protein tTF. Lane 2-8, total proteins induced by IPTG at a concentration of 0 , $0.1,0.2,0.4,0.6,0.8$ and $1 \mathrm{mmol} / 1$, respectively; lane 9 , final fusion protein tTF purified with a nickel affinity column. tTF, truncated tissue factor; M, protein marker.

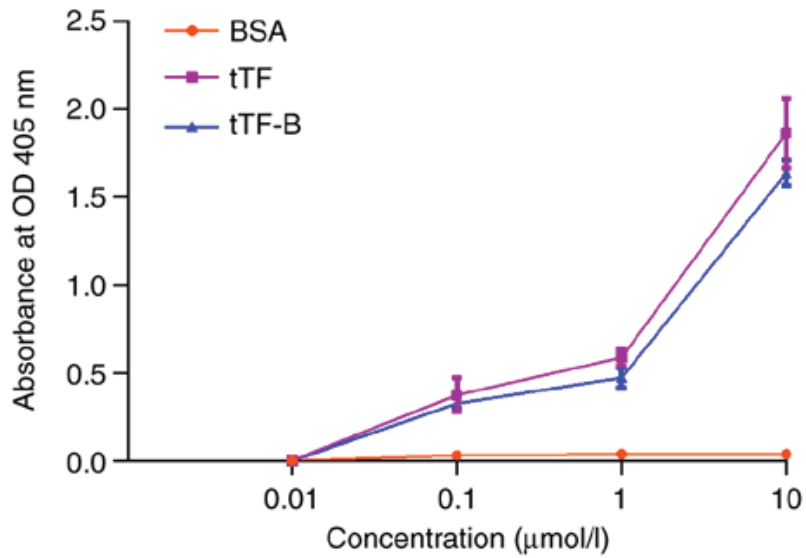

Figure 5. Factor X coagulation assay. The ability of tTF-B and control protein tTF to facilitate the specific proteolytic activation of factor $\mathrm{X}$ by factor VII was assessed using a factor $\mathrm{X}$ coagulation assay; BSA was used as the negative control. The tTF-B retained the ability of the tTF moiety to induce blood coagulation. tTF, truncated tissue factor; B, biotin; OD, optical density.

concentrations, indicating that $\mathrm{tTF}-\mathrm{B}$ retained the $\mathrm{tTF}$ moiety when inducing blood coagulation.

Verification of $B / S A$ binding ability. A competitive ELISA was used to detect the in vitro binding ability of tTF-B and mAb-SA (Fig. 6). The results revealed that the EDC reaction did not impair the B-binding ability of SA. The tTF-B-binding capacity of the mAb-SA conjugate was $73 \%$ compared with

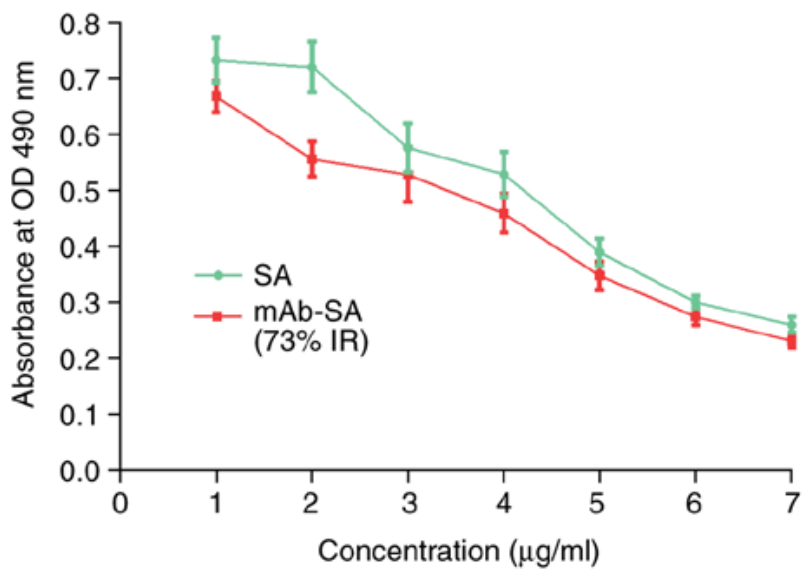

Figure 6. Competitive ELISA of SA vs. mAb-SA on tTF-B. Competitive ELISA was performed to determine the tTF-B-binding capacity of $\mathrm{SA} / \mathrm{mAb}-\mathrm{SA}$. The tTF-B-binding capacity of mAb-SA conjugate was $73 \%$ relative to that of unmodified SA. mAb, monoclonal antibody; SA, streptavidin; tTF, truncated tissue factor; B, biotin; OD, optical density; IR, inhibition rate.

that of unmodified SA. Therefore, the in vitro use of the mAb-SA:tTF-B system may also be of value for in vivo studies.

In vivo distribution of $m A b-S A$. Live imaging was performed to assess the distribution of $\mathrm{mAb}-\mathrm{SA}$ in tumor-bearing mice. A variety of Cy5-labeled reagents and saline (blank control) were intravenously injected, and the fluorescent signals were 


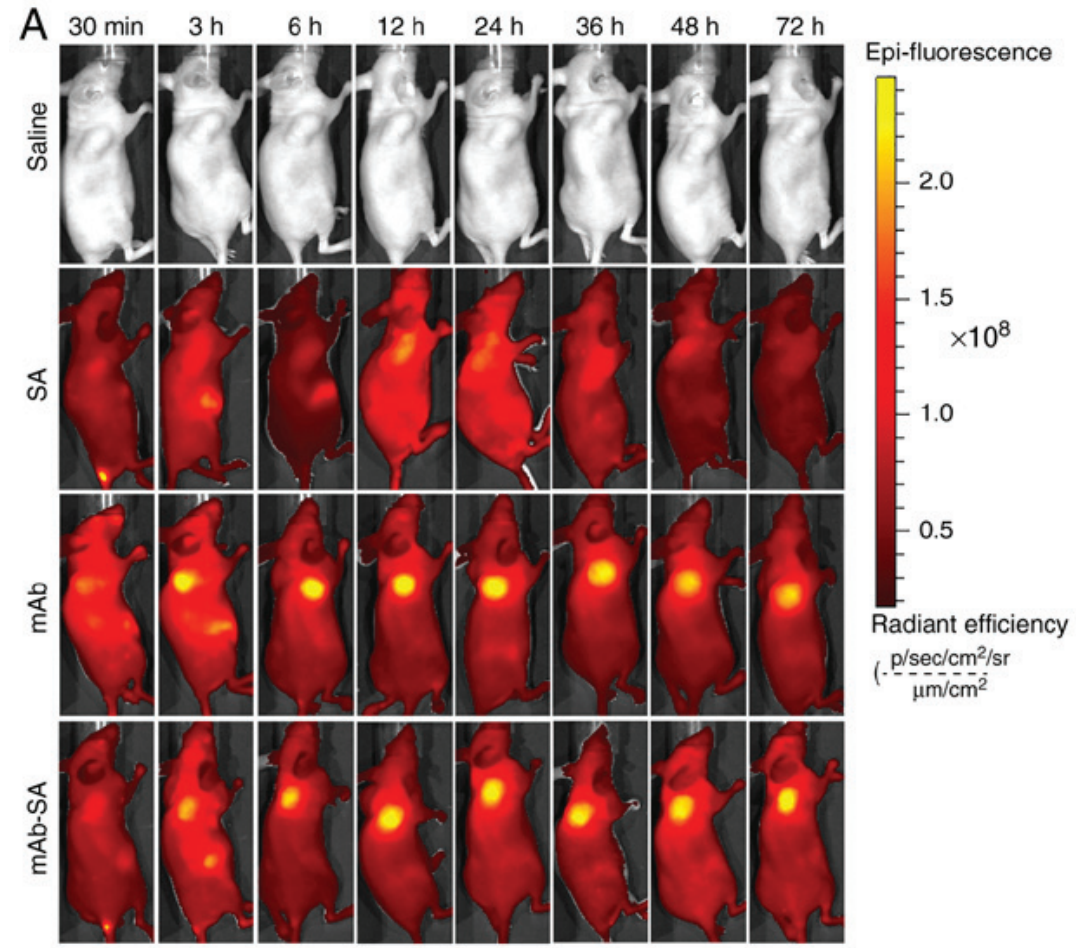

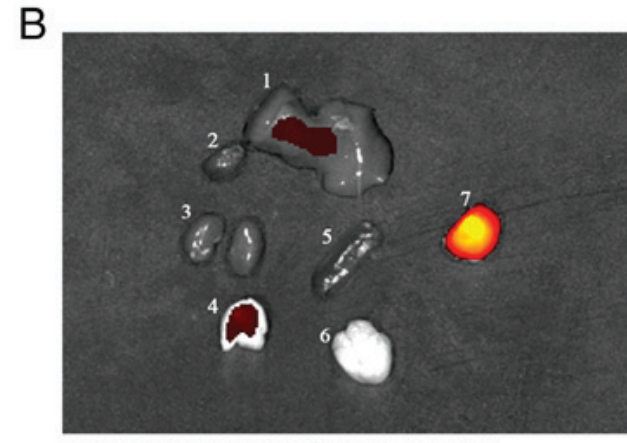

1. Liver 2. Heart 3. Kidney 4. Lung

5. Spleen 6. Brain 7. Tumor

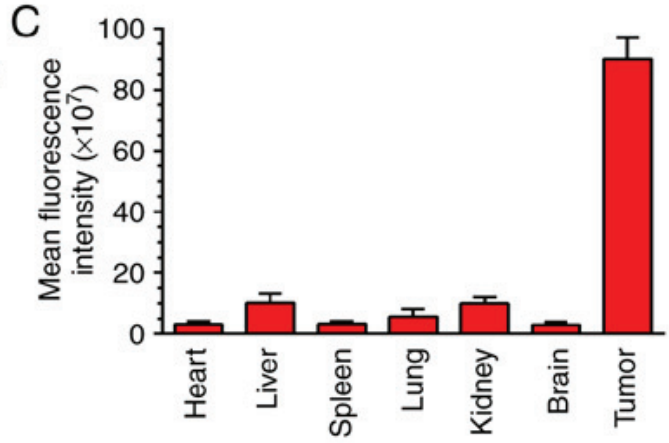

Figure 7. Representative live imaging of Cy5-labeled agents in tumor-bearing mice. (A) In vivo imaging of HepG2 xenograft-bearing nude mice at various time points following administration of saline, SA, mAb and mAb-SA. (B) Fluorescence imaging of major normal organs and tumor tissues from the mAb-SA-Cy5 treatment group at $72 \mathrm{~h}$ following administration. (C) Mean fluorescence intensities of major organs and tumors from the mAb-SA-Cy5 treatment group. $\mathrm{mAb}$, monoclonal antibody; SA, streptavidin; Cy5, cyanine-5.

detected at various time points. As presented in Fig. 7A, Cy5-labeled $\mathrm{mAb}$ and $\mathrm{mAb}-\mathrm{SA}$ were detected in the tumor area at $3 \mathrm{~h}$ following intravenous injection. The peaks in fluorescent signals were similar at $24 \mathrm{~h}$; however, no SA-Cy5 fluorescent signal was observed in tumor tissues. The fluorescent signals in the $\mathrm{mAb}$ and $\mathrm{mAb}-\mathrm{SA}-\mathrm{Cy} 5$ treatment groups remained strong at $72 \mathrm{~h}$ (Fig. 7B and C). Weak Cy5 fluorescence signals were detected in the major organs; the fluorescence intensity ratio of tumor to non-tumor tissue was $\sim 8.83-29.80$ in mice injected with mAb-SA-Cy5. The results of the present study suggested that the mAb-SA conjugate was able to selectively target tumor tissues, but was not retained by normal organs.

Antitumor activity of the $m A b-S A: t T F-B$ system. The antitumor activity of the mAb-SA:tTF-B system was evaluated in HepG2 xenograft-bearing nude mice. Tumor growth curves are presented in Fig. 8A. Overall, tumors in mice treated with mAb-SA:tTF-B exhibited decreased growth compared with other treatment groups. Tumor regression was also only observed following the third treatment on day 6 . This indicated that the two-step coagulation approach was able to effectively inhibit the growth of HepG2 xenografts and may result in tumor regression. In addition, the results revealed that $\mathrm{mAb}$-SA alone could markedly affect tumor growth rate (mAb-SA vs. saline, $\mathrm{P}<0.05$ ). These results are supported by the final tumor weights (Fig. 8B) of mice in different treatment groups after treatment for 12 days.

In vivo intravascular thrombosis is observed following $m A b-S a: t T F-B$ treatment. H\&E staining was performed to
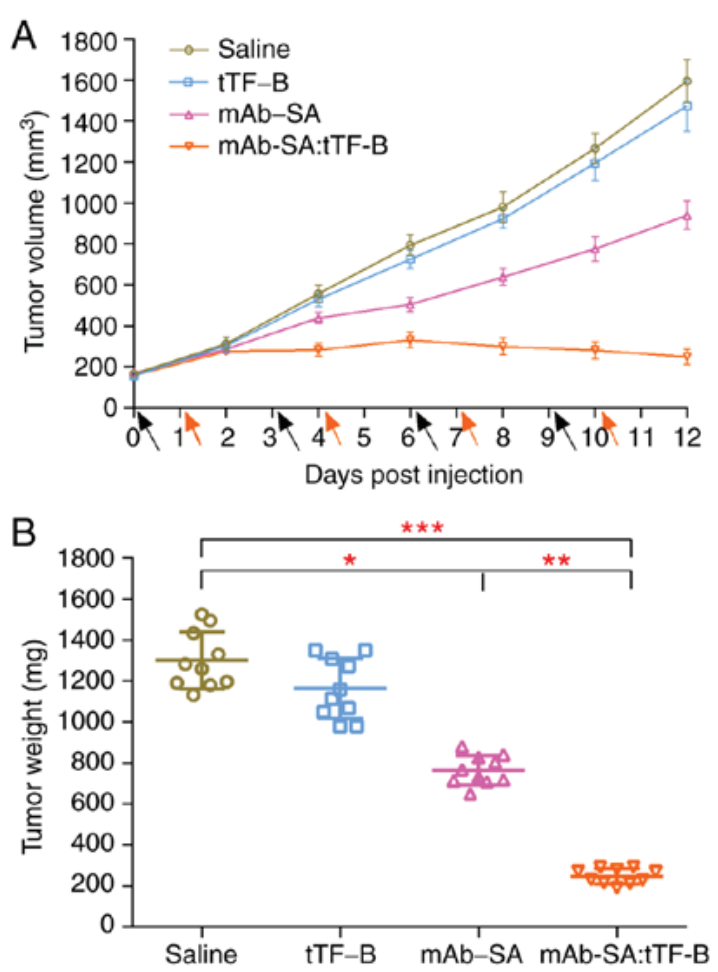

Figure 8. Antitumor efficiency studies on HepG2 tumor-bearing nude mouse models. (A) Mean tumor size was recorded for 12 days following the first treatment dose. Mice in various treatment groups received four intravenous injections of saline, mAb-SA, tTF-B, and mAb-SA:tTF-B at the indicated time (black arrows). Orange arrows indicate the time points at which the mAb-SA:tTF-B treatment group received tTF-B. (B) Mean tumor weight was evaluated after 12 days of treatment. ${ }^{*} \mathrm{P}<0.05 ;{ }^{* *} \mathrm{P}<0.01 ;{ }^{*}{ }^{* * *} \mathrm{P}<0.001 . \mathrm{mAb}$ monoclonal antibody; SA, streptavidin; tTF, truncated tissue factor; B, biotin. 

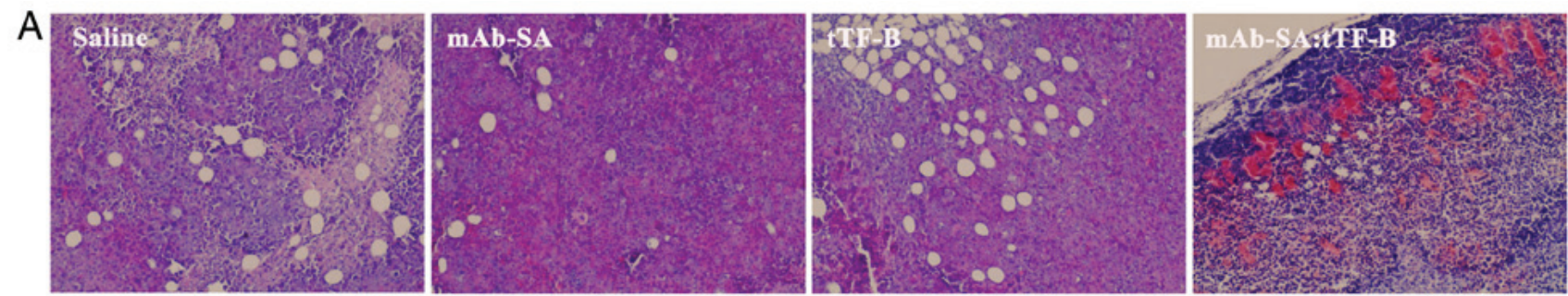

B
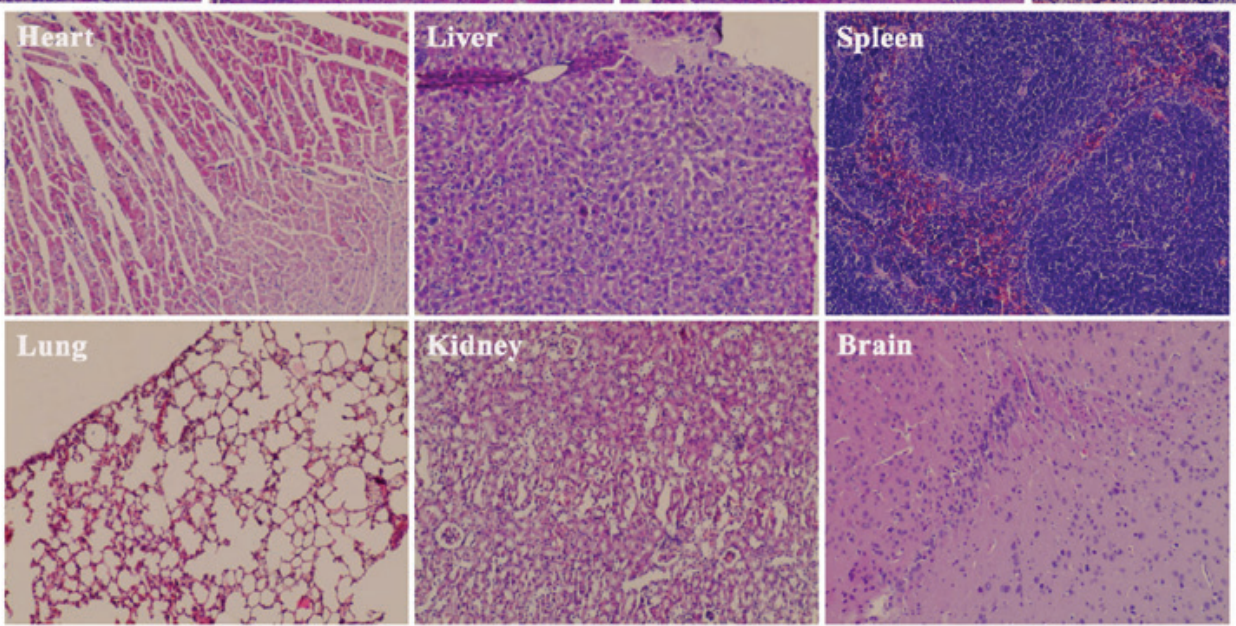

Figure 9. H\&E staining of tumor tissues in nude mice and thrombotic risk evaluation in normal tissues of mAb-SA:tTF-B-treated mice. (A) H\&E-stained tumor tissues from different treatment groups (magnification, x200). (B) H\&E-stained normal tissues from the mAb-SA:tTF-B treatment group (magnification, $\mathrm{x} 200)$. H\&E, hematoxylin and eosin; mAb, monoclonal antibody; SA, streptavidin; tTF, truncated tissue factor; B, biotin.

observe histological changes in the tumor tissues of mice from the different treatment groups. Extensive thrombosis (estimated at $\sim 80 \%$ ) in blood vessels and necrosis were observed in the tumor tissues of mice treated with mAb-SA:tTF-B (Fig. 9A). In contrast, decreased intravascular embolization was exhibited in the other treatment groups. These results confirmed that the $\mathrm{mAb}$-SA conjugate retained tumor vasculature-targeting ability and induced intravascular thrombosis in vivo by directing tTF-B to the vascular endothelial cell surface, thereby causing inhibition of tumor growth and promoting tumor regression. Major organs from the mAb-SA:tTF-B treatment group did not exhibit any visible ectopic embolism or overt tissue injury (Fig. 9B).

\section{Discussion}

Vascular targeting therapy was developed to selectively induce thrombosis in the vasculature of solid tumors. There are several advantages of this antitumor strategy (39). A local occlusion in the tumor vasculature may cause subsequent cell death due to the deprivation of adequate oxygen and nutrient supply. Drugs can also directly target universal tumor vascular endothelium cells in the blood; it has been reported that tumor vascular endothelial cells are unlikely to transform or acquire mutations (40). Therefore, this targeting therapy may be widely applicable. Conversely, conventional therapies, including chemotherapy and radiotherapy, although widely used, may exert cytotoxic effects on normal tissues $(41,42)$. Numerous reports have demonstrated that the tTF ligand, which targets a specific antigen, can markedly inhibit tumor growth and promote tumor regression by selectively inducing intratumoral thrombosis (43-45); tTF has been conjugated with various peptides to improve its efficacy, including SP5.2, NGR peptide and arginylglycylaspartic acid, or their derivatives. However, these fusion proteins require multiple administrations to achieve complete thrombosis in the tumor vasculature, which prevents the use of this strategy in clinical trials. This may be attributed to the target's low affinity for the targeting moiety and poor distribution (46). Therefore, to improve the antitumor efficacy of this ligand-directed approach, it is important to find a suitable tTF ligand delivery moiety and ensure it has a suitable tumor-specific receptor, which is also expressed in solid tumors.

NRP-1 is highly expressed in the endothelial cells of a variety of tumors, and exerts a positive effect on tumor angiogenesis, progression and metastasis (47-48). Therefore, the anti-NRP-1 mAb has been previously demonstrated to be a promising delivery method that may be used to target tumor vessels (14). To increase the concentration of tTF in tumor blood vessels and minimize its distribution in normal tissues, the present study introduced the SA/B system, which is characterized by high binding affinity.

In this approach, the preparation of $\mathrm{mAb}-\mathrm{SA}$ conjugate was performed using EDC and sulfo-NHS. Sephadex G200 column chromatography was used to purify and unify the products. Native SDS-PAGE analysis was subsequently conducted to characterize the mAb-SA conjugate that was synthesized. The results indicated that a homogeneous conjugate product was obtained, with a theoretical molecular weight of $\sim 210 \mathrm{kDa}$. A B-labeling kit was used to prepare tTF-B after the fusion protein tTF had been generated and purified. The in vitro activity of the mAb-SA:tTF-B system was tested prior to in vivo investigations. In vitro experiments, including confocal immunofluorescence, flow cytometry and factor $\mathrm{X}$ 
activation, indicated that mAb-SA preserved the antibody's binding ability in HUVECs, which highly express NRP-1 (35). The results also demonstrated that tTF-B retained the ability to induce blood coagulation. Furthermore, the mAb-SA:tTF-B system was assessed using competitive ELISA, which demonstrated stable binding between mAb-SA and tTF-B. A subcutaneous tumor-bearing nude mouse model was established to identify the in vivo feasibility of the mAb-SA:tTF-B system. The in vivo distribution and tumor-targeting efficacy of mAb-SA was evaluated using live imaging. An intense fluorescent signal was observed in the tumor area after $3 \mathrm{~h}$; this fluorescence persisted for $72 \mathrm{~h}$. Conversely, weak fluorescence was observed in healthy organs. This suggested that mAb-SA was able to selectively target tumor tissues by interacting with NRP-1 on the vascular endothelial cell surface. In the antitumor activity studies, the mAb-SA conjugate was used to localize tumors, with the conjugate accumulating for $24 \mathrm{~h}$ until the concentration reached its peak. tTF-B was subsequently administered and captured by SA. Data from the growth inhibition assay demonstrated that tumor size decreased after day 6 , and that the mean tumor volume and weight on day 12 were reduced compared with the other treatment groups. Histological analysis revealed that the mAb-SA:tTF-B system induced extensive thrombosis in tumor vessels. No visible ectopic embolism or injury was observed in normal organs, which reflects the robust biological targeting ability of this system.

In conclusion, an antitumor composite system based on vascular targeting was successfully constructed in the present study. In vitro experiments and in vivo studies demonstrated that the mAb-SA:tTF-B system effectively inhibited tumor growth and promoted tumor regression by selectively targeting tumor blood vessels and inducing complete vascular infarction. The introduction of the SA/B system is a promising approach for improving tTF-ligand coagulation efficiency and antitumor activity. Therefore, the present study may provide novel insight for the development of vasculature-targeting antitumor treatments.

\section{Acknowledgements}

Not applicable.

\section{Funding}

This study was supported by the National Natural Science Foundation of China (grant. nos. 81773770) and the Science and Technology Foundation of Fujian Province, China (grant nos. 2018R1036-1, 2018R1036-3 and 2019R1001-2).

\section{Availability of data and materials}

The datasets generated and analyzed during the present study are available from the corresponding author upon reasonable request.

\section{Authors' contributions}

PX drafted the manuscript. PX, MZ and SW performed the experiments. JY, FL, TW and PX designed the study. TL, CL,
LiW and LaW performed data analysis. JY and PX contributed to the manuscript revisions. All authors reviewed the manuscript. All authors have read and approved the final version of the manuscript for publication.

\section{Ethics approval and consent to participate}

All the animal experiments performed in this study were approved by the Ethics Committee of Xiamen University.

\section{Patient consent for publication}

Not applicable.

\section{Competing interests}

The authors declare that they have no competing interests.

\section{References}

1. Folkman J: The role of angiogenesis in tumor growth. Semin Cancer Biol 3: 65-71, 1992.

2. Blumberg N: Tumor angiogenesis factor. Speculations on an approach to cancer chemotherapy. Yale J Biol Med 47: 71-81, 1974.

3. Milowsky MI, Nanus DM, Kostakoglu L, Sheehan CE, Vallabhajosula S, Goldsmith SJ, Ross JS and Bander NH: Vascular targeted therapy with anti-prostate-specific membrane antigen monoclonal antibody J591 in advanced solid tumors. J Clin Oncol 25: 540-547, 2007.

4. Bose D, Meric-Bernstam F, Hofstetter W, Reardon DA, Flaherty KT and Ellis LM: Vascular endothelial growth factor targeted therapy in the perioperative setting: Implications for patient care. Lancet Oncol 11: 373-382, 2010.

5. Kessler T, Bieker R, Padró T, Schwöppe C, Persigehl T, Bremer C, Kreuter M, Berdel WE and Mesters RM: Inhibition of tumor growth by RGD peptide-directed delivery of truncated tissue factor to the tumor vasculature. Clin Cancer Res 11: 6317-6324, 2005.

6. Schwöppe C, Kessler T, Persigehl T, Liersch R, Hintelmann H, Dreischalück J, Ring J, Bremer C, Heindel W, Mesters RM and Berdel WE: Tissue-factor fusion proteins induce occlusion of tumor vessels. Thromb Res 125 (Suppl 2): S143-S150, 2010.

7. Furie B and Furie BC: The molecular basis of coagulation. Cell 53: 505-518, 1988.

8. Persigehl T, Ring J, Bremer C, Heindel W, Holtmeier R, Stypmann J, Claesener M, Hermann S, Schäfers M, Zerbst C, et al: Non-invasive monitoring of tumor-vessel infarction by retargeted truncated tissue factor tTF-NGR using multi-modal imaging. Angiogenesis 17: 235-246, 2014.

9. Alessi P, Ebbinghaus C and Neri D: Molecular targeting of angiogenesis. Biochim Biophys Acta 1654: 39-49, 2004.

10. Archer R, Wakabayashi M, Sevilla R, Summers S, King S and Aimes R: Targeting truncated tissue factor with tumor vasculature specific monoclonal antibodies: Developing coaguligands as cancer therapeutics. Cancer Res 67: 14-18, 2007.

11. Kessler T, Schwöppe C, Liersch R, Schliemann C, Hintelmann H, Bieker R, Berdel WE and Mesters RM: Generation of fusion proteins for selective occlusion of tumor vessels. Curr Drug Discov Technol 5: 1-8, 2008.

12. Soker S, Takashima S, Miao HQ, Neufeld G and Klagsbrun M: Neuropilin-1 is expressed by endothelial and tumor cells as an isoform-specific receptor for vascular endothelial growth factor. Cell 92: 735-745, 1998.

13. Wise LM, Veikkola T, Mercer AA, Savory LJ, Fleming SB, Caesar C, Vitali A, Makinen T, Alitalo K and Stacker SA: Vascular endothelial growth factor (VEGF)-like protein from orf virus NZ2 binds to VEGFR2 and neuropilin-1. Proc Natl Acad Sci USA 96: 3071-3076, 1999.

14. Gagnon ML, Bielenberg DR, Gechtman Z, Miao HQ, Takashima S, Soker S and Klagsbrun M: Identification of a natural soluble neuropilin-1 that binds vascular endothelial growth factor: In vivo expression and antitumor activity. Proc Natl Acad Sci USA 97: 2573-2578, 2000. 
15. Bergé M, Allanic D, Bonnin P, de Montrion C, Richard J, Suc M, Boivin JF, Contrerès JO, Lockhart BP, Pocard M, et al: Neuropilin-1 is upregulated in hepatocellular carcinoma and contributes to tumour growth and vascular remodelling. J Hepatol 55: 866-875, 2011.

16. Seifi-Alan M, Shams R, Bandehpour M, Mirfakhraie R and Ghafouri-Fard S: Neuropilin-1 expression is associated with lymph node metastasis in breast cancer tissues. Cancer Manag Res 10: 1969-1974, 2018.

17. Huang X, Molema G, King S, Watkins L, Edgington TS and Thorpe PE: Tumor infarction in mice by antibody-directed targeting of tissue factor to tumor vasculature. Science 275: 547-550, 1997.

18. Thorpe PE: Vascular targeting agents as cancer therapeutics. Clin Cancer Res 10: 415-427, 2004.

19. Hu P, Yan J, Sharifi J, Bai T, Khawli LA and Epstein AL: Comparison of three different targeted tissue factor fusion proteins for inducing tumor vessel thrombosis. Cancer Res 3 : 5046-5053, 2003.

20. Saga T, Weinstein JN, Jeong JM, Heya T, Lee JT, Le N, Paik CH, Sung $C$ and Neumann RD: Two-Step targeting of experimental lung metastases with biotinylated antibody and radiolabeled streptavidin. Cancer Res 54: 2160-2165, 1994.

21. Zhang M, Sakahara H, Yao Z, Saga T, Nakamoto Y, Sato N, Nakada H, Yamashina I and Konishi J: Intravenous avidin chase improved localization of radiolabeled streptavidin in intraperitoneal xenograft pretargeted with biotinylated antibody. Nucl Med Biol 24: 61-64, 1997.

22. Sakahara H and Saga T: Avidin-biotin system for delivery of diagnostic agents. Adv Drug Deliv Rev 37: 89-101, 1999.

23. Liu X, Yang Q, Nakamura C and Miyake J: Avidin-biotinimmobilized liposome column for chromatographic fluorescence on-line analysis of solute-membrane interactions. J Chromatogr B Biomed Sci Appl 750: 51-60, 2001.

24. Medina LA, Calixto SM, Klipper R, Phillips WT and Goins B: Avidin/biotin-liposome system injected in the pleural space for drug delivery to mediastinal lymph nodes. J Pharm Sci 93 2595-2608, 2004

25. Nobs L, Buchegger F, Gurny R and Allémann E: Biodegradable nanoparticles for direct or two-step tumor immunotargeting. Bioconjug Chem 17: 139-145, 2006.

26. Kheirolomoom A, Dayton PA, Lum AF, Little E, Paoli EE, Zheng $\mathrm{H}$ and Ferrara KW: Acoustically-active microbubbles conjugated to liposomes: Characterization of a proposed drug delivery vehicle. J Control Release 118: 275-284, 2007.

27. Goldenberg DM, Sharkey RM, Paganelli G, Barbet J and Chatal JF: Antibody pretargeting advances cancer radioimmunodetection and radioimmunotherapy. J Clin Oncol 24: 823-834, 2006.

28. Urbano N, Papi S, Ginanneschi M, De Santis R, Pace S, Lindstedt R, Ferrari L, Choi S, Paganelli G and Chinol M: Evaluation of a new biotin-DOTA conjugate for pretargeted antibody-guided radioimmunotherapy (PAGRIT). Eur J Nucl Med Mol Imaging 34: 68-77, 2007.

29. Zeng F, Luo F, Lv S, Zhang H, Cao C, Chen X, Wang S, Li Z, Wang X, Dou X, et al: A monoclonal antibody targeting neuropilin-1 inhibits adhesion of MCF7 breast cancer cells to fibronectin by suppressing the FAK/p130cas signaling pathway. Anticancer Drugs 25: 663-672, 2014.

30. Chen F, Nielsen S and Zenobi R: Understanding chemical reactivity for homo- and heterobifunctional protein cross-linking agents. J Mass Spectrom 48: 807-812, 2013.

31. Nwe K, Milenic DE, Ray GL, Kim YS and Brechbiel MW: Preparation of cystamine core dendrimer and antibody-dendrimer conjugates for MRI angiography. Mol Pharm 9: 374-381, 2012.
32. Neerman MF, Zhang W, Parrish AR and Simanek EE: In vitro and in vivo evaluation of a melamine dendrimer as a vehicle for drug delivery. Int J Pharm 281: 129-132, 2004.

33. Chan EC and Ho PC: Preparation and characterization of immunogens for antibody production against metanephrine and normetanephrine. J Immunol Methods 266: 143-154, 2002.

34. Xu ZC, Shen HX, Chen C, Ma L, Li WZ, Wang L and Geng ZM: Neuropilin-1 promotes primary liver cancer progression by potentiating the activity of hepatic stellate cells. Oncol Lett 15: 2245-2251, 2018.

35. Wang L, Zeng H, Wang P, Soker S and Mukhopadhyay D: Neuropilin-1-mediated vascular permeability Factor/Vascular endothelial growth Factor-dependent endothelial cell migration. J Biol Chem 278: 48848-48860, 2003.

36. Chen X, Lv H, Ye M, Wang S, Ni E, Zeng F, Cao C, Luo F and Yan J: Novel superparamagnetic iron oxide nanoparticles for tumor embolization application: Preparation, characterization and double targeting. Int J Pharm 426: 248-255, 2012.

37. Hylarides MD, Mallett RW and Meyer DL: A robust method for the preparation and purification of Antibody/streptavidin conjugates. Bioconjug Chem 12: 421-427, 2001.

38. Liao MY, Kuo MY, Lu TY, Wang YP and Wu HC: Generation of an anti-EpCAM antibody and epigenetic regulation of EpCAM in colorectal cancer. Int J Oncol 46: 1788-1800, 2015.

39. Gottstein C, Wels W, Ober B and Thorpe PE: Generation and characterization of recombinant vascular targeting agents from hybridoma cell lines. Biotechniques 30: 190-194, 2001.

40. Hu Z, Rao B, Chen S and Duanmu J: Selective and effective killing of angiogenic vascular endothelial cells and cancer cells by targeting tissue factor using a factor VII-targeted photodynamic therapy for breast cancer. Breast Cancer Res Treat 126: 589-600, 2011.

41. Rades D, Fehlauer F, Bajrovic A, Mahlmann B, Richter E and Alberti W: Serious adverse effects of amifostine during radiotherapy in head and neck cancer patients. Radiother Oncol 70: 261-264, 2004.

42. Monsuez JJ, Charniot JC, Vignat N and Artigou JY: Cardiac side-effects of cancer chemotherapy. Int J Cardiol 144: 3-15, 2010.

43. Dienst A, Grunow A, Unruh M, Rabausch B, Nör JE, Fries JW and Gottstein C: Specific occlusion of murine and human tumor vasculature by VCAM-1-targeted recombinant fusion proteins. J Natl Cancer Inst 97: 733-747, 2005.

44. Bieker R, Kessler T, Schwöppe C, Padró T, Persigehl T, Bremer C, Dreischalück J, Kolkmeyer A, Heindel W, Mesters RM and Berdel WE: Infarction of tumor vessels by NGR-peptide-directed targeting of tissue factor: Experimental results and first-in-man experience. Blood 113: 5019-5027, 2009.

45. Lv S, Ye M, Wang X, Chen X, Dou X, Dai Y, Dai Y, Zeng F, Luo L, Wang C, et al: A recombined fusion protein SP5.2/tTF induce thrombosis in tumor blood vessel. Neoplasma 62: 531-540, 2015.

46. Schmidt LH, Stucke-Ring J, Brand C, Schliemann C, Harrach S, Muley T, Herpel E, Kessler T, Mohr M, Görlich D, et al: CD13 as target for tissue factor induced tumor vascular infarction in small cell lung cancer. Lung Cancer 113: 121-127, 2017.

47. Pan Q, Chanthery Y, Liang WC, Stawicki S, Mak J, Rathore N, Tong RK, Kowalski J, Yee SF, Pacheco G, et al: Blocking neuropilin-1 function has an additive effect with anti-VEGF to inhibit tumor growth. Cancer Cell 11: 53-67, 2007.

48. Grandclement $\mathrm{C}$ and Borg C: Neuropilins: A new target for cancer therapy. Cancers (Basel) 3: 1899-1928, 2011.

This work is licensed under a Creative Commons

Attribution-NonCommercial-NoDerivatives 4.0 International (CC BY-NC-ND 4.0) License. 